\title{
Humorismo como creación y fortalecimiento de los vínculos en la sociedad red: el caso de los memes sobre filósofos
}

\section{Humorousness as creation and reinforcement of network society: the case of Philosophers memes}

\author{
Violeta Alarcón Zayas ${ }^{1}$ \\ Recibido el 30 de setiembre de 2016 - Aceptado el 9 de enero de 2017
}

\begin{abstract}
RESUMEN: A fin de comprender el funcionamiento del humor en internet y en las redes sociales, nos aproximaremos a los memes a través de una temática concreta: los memes sobre filósofos y pensadores en general, pues conforman una comunidad de sentido muy concreta, además ejemplifican, en su moderada variedad, los mecanismos fundamentales por los que funcionan y se reproducen los memes humorísticos en general. No nos atendremos a una sola teoría sobre el humor, pues la multiplicidad de los memes y su comicidad no se pliega a un sólo modo de funcionar o a un único fin, por ello trabajaremos desde diversos conceptos, desde lo cómico y lo caricaturesco de Baudelaire, lo grotesco carnavalesco de Bajtin, pasando por las teorías sobre el chiste y la risa freudianas hasta las definiciones de humor de Bergson, Pirandello y Koestler. A partir del análisis discursivo ensayaremos una explicación sobre el funcionamiento del humor en los memes como creación, mantenimiento y fortalecimiento de vínculos en la sociedad red a través de los memes.
\end{abstract}

Palabras clave: comicidad, grotesco, risa, crítica social, comunidad

ABSTRACT: With the aim of understanding humor functioning through internet and social network, we will approach memes through a determinate topic: memes about philosophers and thinkers in general since they define a very specific meaning community. We won't adjust to a single theory, because memes' multiplicity and their comicalness can't be submitted by only one way of working or by specific purpose, therefore we will work from different comical concepts, from Baudelaire's comical and caricature notions, Bajtin's carnival grotesque concept, passing through Freud's theories about jokes and laugh, till Bergson, Pirandello and Koestler humor definitions. From the discursive analysis we will try an explanation of how humor works in order to create, to keep and to reinforce social links.

Key words: comicalness, grotesque, laugh, social critic, community.

1 Violeta Alarcón Zayas es Profesora de Lengua y Literatura españolas, Filosofía y Semiótica y Comunicación en Suma-T Academia. Madrid (España). violeala@ucm.es, http://orcid.org/0000-0002-1995-5769. 


\section{Introducción: Los memes en la so- ciedad red}

Cualquier persona con unos conocimientos y manejo mínimos de Internet y más específicamente cualquier usuario de las redes sociales, es decir, cualquier miembro de la "sociedad red" (Castells, 2001), reconoce lo que es un meme, al menos de forma intuitiva. Aunque el concepto de "unidades culturales replicables" ya apareció a finales de los 60 del siglo pasado, bajo diversos nombres como "mnemotipo" "sociogen", "culturgen" o "tipo cultural". El término "meme" fue concebido por el zoólogo y científico Richard Dawkins, en su libro The Selfish Gene (1976) expone la hipótesis memética de la transmisión cultural. Denomina "meme" a la unidad mínima de información que es posible transmitir o imitar. Según Dawkins, los memes conforman la base intelectual de nuestra cultura, al igual que los genes conforman la base de nuestra vida. Años más tarde, el propio Dawkins definió los memes que circulan por Internet como un "secuestro de la idea original", por lo que es evidente que el concepto de meme ha cambiado y evolucionado por sí mismo. En relación a este cambio, investigaciones más recientes los definen como:

"meme" es un término popular para describir la intuitiva y a menudo rápida absorción y difusión de una idea particular en forma de un texto escrito, una imagen, un desplazamiento lingüístico, u otra pieza o unidad de información cultural (ej: un lema, un videoclip, el relato de un evento). (Knobel y Lankshear, 2005: 1)

Estos autores sugieren que la mayoría de los memes no son replicados de manera intacta, sino que pasan por diferentes procesos de reinterpretación y modificación, lo que permite obtener diferentes versiones de un mismo meme, respetando la idea original, lo que a su vez permite su propagación masiva. En la actualidad, internet en general y las redes sociales en particular, junto a la multitud de aplicaciones y programas de edición que facilitan y automatizan su creación y difusión, propician una constante multiplicación de memes de todo tipo, tanto el reenvío del mismo, como las diversas versiones y modificaciones del original. Con la particularidad de que su autoría pierde relevancia, convirtiéndose en emisores ellos mismos y recuperando el anonimato de la cultura popular, como solían ser los relatos, mitos, leyendas, refranes o chistes de transmisión oral, en los que la autoría, en un principio, resultaba irrelevante.

Para el análisis que se propone en este artículo, se parte de la consideración, junto a autores como Deacon y Kilpinen, de que el estudio de los memes se subsume a la semiótica en general y que una síntesis entre ambas no sólo es posible sino muy enriquecedora para ambas, sobre todo a la hora de los estudios socioculturales:

(..) los semióticos y los estudiosos de la memética pueden beneficiarse ambos 
a partir del reconocimiento mutuo, lo cual hasta ahora se ha dado de manera insuficiente en algunos casos o ni siquiera ha ocurrido en otros, como ya dije. Aunque los estudios de memética no han revelado hasta ahora ningún secreto desconocido a los semióticos, debería obtener el beneficio de la duda en vista a futuras posibilidades. Semejante vía de investigación puede ser un acercamiento a la cultura a través de los significados de las prácticas sociales en lugar de a las convenciones lingüísticas, como ha sido la visión dominante en las semióticas culturales. (Kilpinen, 2008: 16)

Ambos autores parten de presupuestos peirceanos y de la consideración de los memes como signos en cuanto representantes de otras cosas (réplicas) dentro de un sistema determinado en el que interactúa con otros signos.

Un meme es un signo: un objeto físico que, en virtud de alguna característica distintiva, puede ser inscrito por medio de un proceso interpretativo dentro de un gran sistema representando a alguna otra cosa, transmitiendo información en ese sistema y reorganizándolo respecto a algo más. (Deacon, 2004: 7)

Esta descripción subraya el aspecto formal del funcionamiento de los signos: un signo sólo significa dentro de un sistema operante, en otras palabras, tiene sentido sólo en virtud del sentido de los otros signos del sistema. Esta cadena de interpretantes puede ser de distintos tipos: signos, definiciones, funciones proposicionales, signos de otro sistema, etc.

Según Peirce (1984) pensamos sólo con signos, que aunque para definirlos los separa en: iconos, indices y símbolos, -en función de los estados mentales en los que se generan y que suscitan-, son de naturaleza mixta. Deacon defiende que el aspecto icónico es la esencia del concepto de meme, es decir, los memes se definirían fundamentalmente por la propiedad de la semejanza, que despierta en la mente ideas similares a lo que representan. No obstante, no olvidaremos aquí el elemento simbólico en los memes, dado que las partes simbólicas de los signos son los conceptos, y del hecho de que sólo a partir de ellos se pueden crear otros nuevos. Según la teoría peirceana razonar consiste en ordenar los símbolos y hallar la verdad. Un símbolo se extiende entre los individuos y en su uso y experiencia crece su significado, el cual evoluciona ampliando matices o cambiando incluso su significado o idea primigenia, y así funcionan los memes como réplicas que no sólo mantienen su semejanza con el original, sino que lo desarrollan y/o lo modifican.

\section{Humorismo y comicidad en los memes}

Una de las características más comunes de los memes es su carácter cómico y/o humorístico. El humor aquí nos interesa como mecanismo social que 
como cualquier otro proceso de comunicación de creación y mantenimiento de vínculos dentro de un grupo social o cultura, entendida conforme a la definición de Hall (1997), es decir, como un proceso en base a unos sentidos compartidos por una comunidad. Según Hall la producción de sentidos depende de la representación, la cual supone relacionar tres órdenes de cosas: "el mundo de las cosas", "el mundo de los conceptos" y "los signos", que "están por" o comunican los conceptos. Estos órdenes deben ser vinculados y fijados para que se puedan traducir entre ellos. Por esto, la interpretación se sostiene por el uso activo del código por parte del emisor y por la interpretación del mismo que hace el receptor mediante la decodificación.

El humor forma parte de un lenguaje particular, y posee sus propios códigos de interpretación dentro de la comunidad de sentido que en este caso se trata prioritariamente de una comunidad virtual. Esta sociedad red se distingue fundamentalmente según Castells de las sociedades físicas porque permite que los individuos desarrollen sus proyectos y aspiraciones personales atravesando los límites materiales de lo cotidiano, tanto en el lugar de residencia, como el laboral, creando así redes de afinidades más allá de las limitaciones geográficas. Es decir, Internet no es solo un instrumento, sino que es un medio para todo, que permite desarrollar la sociabilidad, pero no cambia los comporta- mientos, por ejemplo los chistes han sido siempre los mismos (poner esto luego), los comportamientos "se apropian” de Internet, por lo que amplían sus posibilidades y las refuerzan. En Internet se articula la sociedad red, pues se trata de un medio de comunicación, interacción y organización social, donde como veremos los memes, en especial desde su perspectiva humorística, juegan un papel relevante para dicha sociabilización. De hecho los memes en sus diferentes formatos funcionan socialmente como los chistes orales, de forma anónima y por ello con cierta autonomía, y siendo usados como medio de reconocimiento de la identidad individual como inserta en una comunidad:

Un chiste nunca es mío. Párame si ya lo conoces, dice quien cuenta chistes, cuando se dispone a compartir su última adquisición. Está en lo cierto al asumir que otros también deben contarlo: un chiste circula. El chiste es esta posesión impersonal. No lleva la firma de nadie. Me lo contaron, pero no lo inventé; estaba bajo mi custodia y decido pasarlo, que circule. No se refiere a ninguno de nosotros. No habla de ti ni de mí. Tiene una vida propia.

Sale... como una detonación, como una risa, un estornudo; como un orgasmo, como una pequeña explosión, un desbordamiento. Contarlo quiere decir: aquí estoy. Sé lo suficientemente como para apreciar este chiste. Soy lo suficientemente sociable y expresiva como para contarlo a 
otros. Me encanta divertir. Me encanta figurar. Me encanta que me valoren. Me encanta sentirme competente. Me encanta estar detrás de mi cara y conducir este pequeño vehículo hasta su pronto destino... y luego salirme. Estoy en el mundo, que tiene muchas cosas que no son yo y que yo valoro. (Sontag, 1995: 228)

Desde el análisis semiótico discursivo desentrañaremos los mecanismos por los que los memes provocan la risa -0 la sonrisa-, gracias a una mezcla heterogénea de técnicas y mecanismos que conjugan lo meramente visual con lo verbal. El humor en los memes no funciona por tanto siempre como chistes en el sentido que define Freud (1927), como una ganancia de placer humorístico procedente del ahorro de energía psíquica o esfuerzo que se invertiría a través de otro afecto displacentero como podrían ser la angustia, el espanto, el miedo o la rabia. Aunque estos textos verbo-visuales comparten con la definición de chiste de Freud (1905) la premeditación, el montaje de una escena y por supuesto la ganancia de placer en el receptor, no lo consiguen siempre mediante la risa liberadora del inconsciente, ni necesariamente librando de un esfuerzo o un displacer. Se detectan en los memes una comicidad diversa, en la que observamos el concepto de humor de Koestler (2002) como cortocircuito cognitivo juega un papel fundamental, o el humorismo que explica Pirandello (2007) como "sentimiento de lo contrario", frente a la mera comi- cidad como "percepción de lo contrario", entrando a jugar otros factores psicosociales, afectivos e ideológicos.

En base a esta afectividad humorística por la que funcionan los memes para la creación y consolidación de los vínculos sociales, la temática filosófica nos parece significativa para analizar su funcionamiento por ser un tema muy concreto, que señala así mismo a un grupo social muy definido y estable: estudiantes, profesores e intelectuales en general que tienen y/o han tenido un contacto directo con la filosofía.

\section{Mecanismos humorísticos y fun- ciones del humor en los memes}

\subsection{Juegos del lenguaje: la homofonía}

Además de la importancia de la imagen, el meme se sirve de la palabra como material fundamental por su plasticidad y flexibilidad, aprovechando sus propiedades polisémicas, su multiplicidad de acepciones en función del contexto, sus posibilidades de homofonía, sinonimia, etc. Se vale a sí mismo de su potencialidad creativa, a través de la condensación, el desplazamiento, las formaciones sustitutivas, la figuración, las paradojas, la simbolización, la elipsis, etc. En estos usos lúdicos e ingeniosos de las palabras, es característico del meme la brevedad, que permite la comprensión instantánea.

En los siguientes ejemplos (figuras 1 y 2) se juega con el fenómeno lingüístico de la 
homofonía. Para poder comprender estos memes son precisos por un lado unos conocimientos culturales mínimos sobre Inmanuel Kant: reconocer al menos el apellido del filósofo, y por otra parte no es necesario dominar el inglés, puesto que se entiende con unas nociones lingüísticas muy básicas de este idioma: la contracción de la negación del modal can $(c a n ' t)$, así como la grafía $I$ que en inglés cumple la función de pronombre personal de la primera persona del singular. Por lo que la restricción a la hora de desentrañar el código no se refiere al dominio de la lengua. Estos conocimientos deben unirse al reconocimiento de que la $I$ al ir seguida de un punto, en realidad funciona como la abreviación del nombre del filósofo: Inmanuel, mediante la letra inicial. Es decir, no equivale a un: "Yo. Kant" a la manera paródica en la

Figura 1. Kant

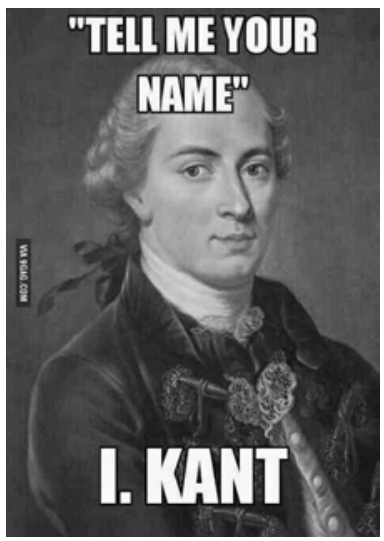

Por otro lado, emplear este tipo de imágenes puede suponer también una parodia de la fórmula recurrente he- que se presentaría un rudimentario usuario de la lengua, al modo de la caricatura estereotípica del lenguaje básico de un hablante no competente que representa por excelencia Tarzán.

Precisamente la posibilidad de doble lectura del texto es la que provoca la hilaridad inmediata, por lo que lo más importante en los siguientes ejemplos es el texto, mientras que el retrato simplemente otorga información o ayuda al reconocimiento del personaje, o funciona como una viñeta, en la que el rostro representa al personaje que emitiría el texto (figura 2) o parte del texto, en ambas dirigiendo la mirada al frente, hacia el enunciatario, que ocupa el lugar de un interlocutor al que no visualizamos ni identificamos y desde el que mira el destinatario del texto.

Figura 2. Kant

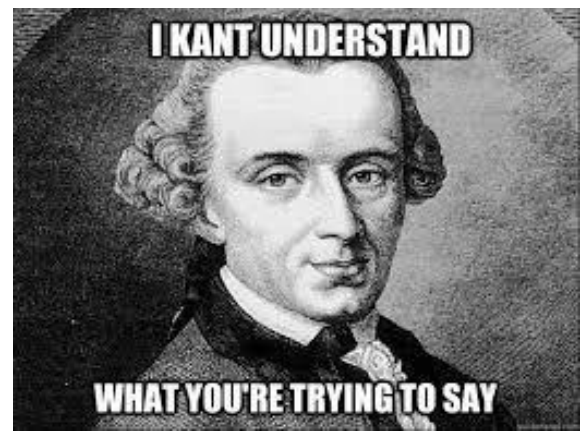

redera de la tradición enciclopédica, de colocar junto a la biografía, citas, ideas, obras, etc. de un personaje, su 
retrato. En este caso no se trata de la ridiculización de Kant o de su pensamiento, sino que el choque cognitivo se genera a partir del lenguaje, es decir, se provoca un quiebre en la expectativa lingüística, un choque cognitivo. Aquí podríamos coincidir provisionalmente con Bergson en que no es necesario que medie la emoción para reírse: "La risa no tiene mayor enemigo que la emoción.(...) Lo cómico, para producir su efecto, exige algo así como una momentánea anestesia del corazón. Se dirige a la inteligencia pura” (Bergson, 1973:15-16). No obstante al referirnos al "puro intelecto" no hablamos de nada "puro", pues como el propio Kant demostró en su Crítica de la Razón Pura, la experiencia es un material fundamental para que el intelecto trabaje, es decir, para entender un chiste contamos con un imaginario aprendido, con unas reglas de comicidad que son culturalmente inculcadas.

Figura 3. Kant

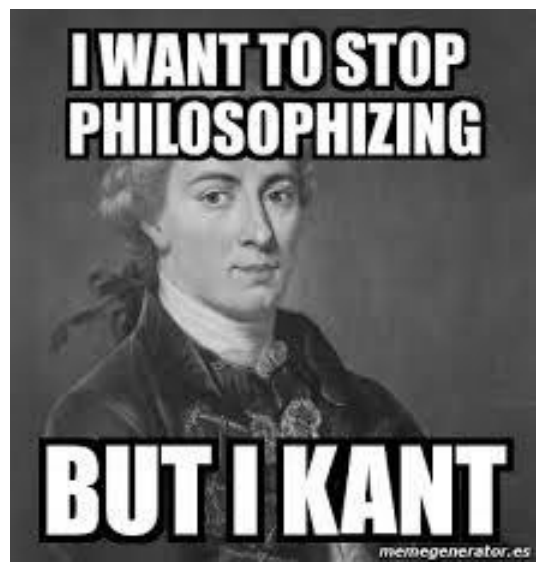

El humor jamás podrá ser universal ni partir de estructuras innatas, sino de códigos aprendidos.

La risa emerge de lo inesperado, pero esa no es condición suficiente. Como afirma Koestler (2002) un hecho deviene cómico por su asociación a dos mar$\cos$ de referencia cognitivamente incompatibles, es decir, el humor surge de una estructura "bisociativa", de la confrontación de dos marcos en principio incompatibles. En este caso se juega con la gramática, la fonética y la semántica, infringiendo la ley ortográfica, pero aprovechando la ambigüedad que produce la homofonía se salva el significado, y este ligerísimo esfuerzo de reelaboración gestáltico, es compensado con la risa. La mente rápidamente recompone el mensaje con sentido, lee el texto aplicando la estructura conocida con el significado más próximo, aunque perciba la "irregularidad".

Figura 4. Hegel

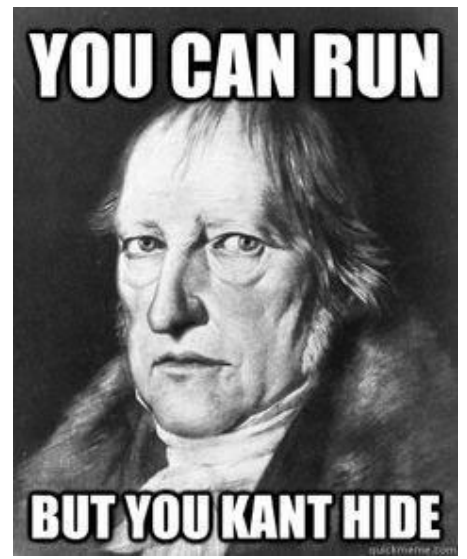


Si bien los dos memes anteriores no requerían un conocimiento especializado para su interpretación, sino que se comprendían con un tinte de cultura general, las figuras 3 y 4 requieren un nivel mayor de conocimientos específicos. Ambos exigen para ser interpretados humorísticamente un manejo mínimo del inglés y aunque incorporan el mismo elemento semántico de la homofonía que las figuras 1 y 2 , implican una cultura filosófica mayor, que sin llegar a exigir el dominio de la jerga, sí supone unos recursos conceptuales básicos y cierto anecdotario sobre la historia de la filosofía.

La figura 4 exige un conocimiento más profundo, no de Kant, sino del personaje que aparece retratado: Hegel, lo cual podría resultar ambiguo y llevar a confusiones sobre la identidad del filósofo de la pintura reproducida en el meme. Aunque se juega aquí con el nombre de Kant, cuyo pensamiento se relaciona en bastantes aspectos con el hegeliano, a menudo como contrapuestos, la parodia en este caso se basa en la dialéctica de Hegel. Al parafrasearla se transmite en esencia la difícil discusión filosófica que presenta la idea de la contradicción como motor de la realidad, aunando la realidad objetiva y la realidad de la conciencia, por lo cual tendiendo una trampa que hace imposible "escapar" teóricamente, dado que se trata de una maquinaria conceptual que cuanto más se niega, más se afirma.

El humor por tanto parte en este caso de la empatía, del reconocimiento de una comunidad, de una tradición, de una cultura común. No exige la reflexión de quien maneja dichos conocimientos, dicha matriz de sentido, sino que aquí afirmamos junto a Pirandello (2007: 93) que: “(...) debido a la reflexión, insertada en la semilla del sentimiento, como un visco, se despiertan las ideas y las imágenes contrapuestas". Este estado de perplejidad que surge de la reflexión y que el autor define como "sentimiento de lo contrario" justifica lo humorístico en casos como éste y otros similares que analizaremos en adelante. Es decir, para un sujeto competente, que reconoce el rostro de Hegel y lo identifica con su pensamiento, y una simpatía o antipatía por su pensamiento $\mathrm{y} / \mathrm{o}$ personalidad, la risa emerge inmediatamente, por un lado en base a la complicidad, (por eso se comparte, se difunde por las redes, se busca la aprobación de los miembros del grupo social) y por otro lado por el choque cognitivo que provoca, dentro de una arquitectura de significados y conceptos bien articulados y definidos.

Por otro lado, es evidente que el enunciado tiene un tono amenazante, y esto causa una hilaridad mayor, debido a que se pone en tela de juicio el respeto intelectual que produce la lectura de Hegel. Ridiculizar a una figura venerable resulta siempre catártico, y nos recuerda la función del "realismo grotesco" (Bajtin, 1987), humor heredero de la fiesta carnavalesca medieval donde lo sagrado se torna profano y viceversa, borrando las jerarquías. Es sabido que la obra de Hegel no sólo ha 
sido polémica sino también de difícil y dolorosa comprensión para todos sus lectores, no sólo para generaciones y generaciones de estudiantes, sino para los propios herederos de su pensamiento. Dentro del anecdotario filosófico es sabido que tanto a Marx como a Bakunin la lectura de sus grandes obras la Fenomenología del espiritu y la Ciencia de la Lógica les causaron gran abatimiento, aparte de influir en su pensamiento. De hecho se cuenta que el pensador socialista le regaló al anarquista las obras de Hegel, cuando aún se entendían amistosa y políticamente, advirtiéndole que sería duro de digerir, pero que se trataba de un conocimiento indispensable. Posteriormente Bakunin abandonó dichos libros hastiado, y volvieron a caer en manos de Marx a través de un amigo común. Este relato no es muy conocido fuera del ámbito filosófico, forma parte de sus leyendas, por tanto para un profano, este meme se convierte en un jeroglífico indiscernible que le deja impasible, siendo de difícil decodificación para un destinatario que no forme parte de la comunidad, no obstante es un chiste no circunscrito a una época concreta, dado que el sentido puede ser compartido siempre que la obra de Hegel siga viva en la vida académica e intelectual.

Es bien sabido que un chiste si se tiene que explicar pierde su capacidad humorística. Igualmente traducir un chiste de una cultura a otra, o de un idioma a otro resulta casi siempre un fracaso, pues las estructuras cognitivas son diferentes y predisponen a diversos modos de humor, que a menudo van más allá del conocimiento de una lengua extranjera, sino que requieren una incorporación o asimilación de hábitos, costumbres y creencias que proporcionen una competencia similar a la nativa para comprender el sentido de humor de un grupo social o cultura determinados.

Los memes que vamos a analizar a continuación compartirán con estos últimos el requisito de unos conocimientos básicos de la jerga filosófica o psicológica y de la historia de la disciplina. Funcionarán todos como elemento que refuerza el sentido de comunidad.

\subsection{Parodias del lenguaje filosófico}

Existe una tipología de memes que se puede considerar continuadores de la parodia sacra medieval que estudia Bajtin (1989) en cuanto a la ridiculización del retoricismo escolar, el barroquismo y el profuso empleo de citas. En lugar de utilizar la estructura clásica del chiste con un final inesperado, se trata de una parodia en la que se pone en evidencia un elemento retórico, un contenido formalizado en una frase que pertenece al imaginario común, en un estado de atemporalidad si no sagrada, de ritual aceptación, y al degradarse y ponerse en una situación ordinaria, provoca el "transformismo" del que habla Bajtin un "híbrido intencionado":

En la palabra paródica convergen, y en cierta manera se cruzan, dos estilos, 
dos "lenguajes" (interlingüísticos): el lenguaje parodiado, -por ejemplo el de un poema heroico- y el que parodia- el lenguaje prosaico vulgar, el familiar, el familiar oral, el de los géneros realistas, el lenguaje literario "normal", "sano", tal y como se lo imagina el autor de la parodia. (Bajtin, 1989: 441)

Los siguientes memes reiteran una misma estructura dialogada: el pensador o filósofo emplea una frase en lenguaje ordinario, a menudo soez, y alguien a quien no identificamos pero imaginamos su discípulo, alumno, editor, traductor, etc., le replica: "Pero (nombre en vocativo) no podemos poner eso", y entonces se escribe la cita literal o parafraseada, normalmente la más célebre o difundida del pensador.

Ante estos textos verbovisuales puede haber tres tipos de receptores que al enfrentarse a ellos capten su comicidad, en base a distinto nivel de competencia. Por un lado provoca la risa (o

Figura 5. Sócrates

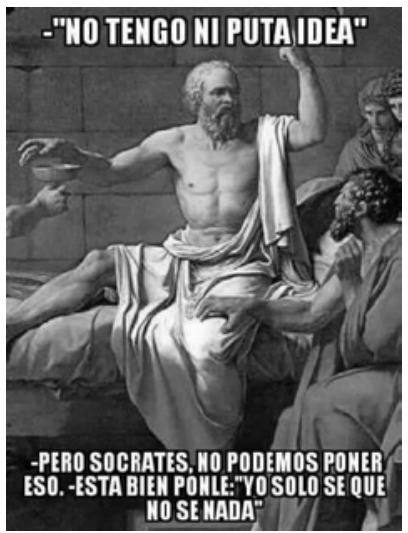

quizás sólo la sonrisa) de alguien que conoce tanto las obras y los autores y es capaz de relacionarlos. De hecho un receptor que reconoce a Sócrates en la imagen y lee "no tengo ni puta idea" podría anticipar el resultado, pero prevé el desenlace con total seguridad al leer "Sócrates, no podemos poner eso". El hecho de atribuir a estas citas un uso eufemístico debido a cierto escrúpulo o censura de un poder invisible que decreta cómo se puede y no decir lo que se dice, supone una reivindicación, una forma de desacralización del lenguaje filosófico, a menudo parodiado por considerarse ininteligible, elitista y oscuro. En estos dos casos, la crítica procedería de que las frases son demasiado sintéticas o abiertas a la interpretación. Aquí nos encontramos más bien con que se parodia la ceremonialidad y el uso elaborado del lenguaje. Como si fuera eufemístico se simula un retorno a un hipotético génesis en el que la expresión original surgió espontánea en lenguaje soez, pero claro e inteligible.

Figura 6. Pascal

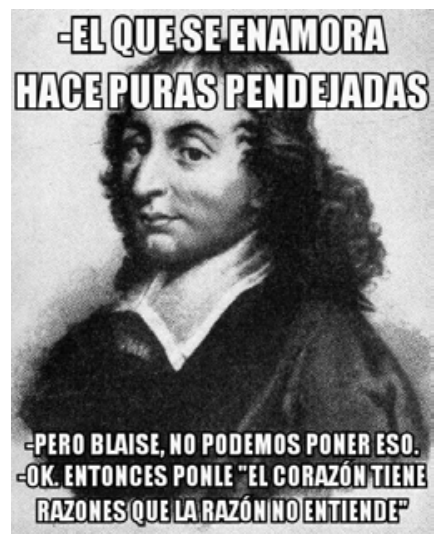


Para un receptor familiarizado con la cita del pensador, la sorpresa no surge al final del diálogo. No obstante, para quien no identifique el retrato del filósofo o desconozca su relación con el enunciado, al tratarse de una cita tan popular (más que Pascal), podrá prever la frase final, dado que está tan extendida en el habla cotidiana que se utiliza ya como refrán, ignorando al autor, e incorporándose al repertorio de la sabiduría popular. Por tanto, entre quienes no identifiquen al autor puede haber receptores competentes que sí reconozcan la cita y se rían al unir dos elementos que permanecían separados en sus esquemas cognitivos. Al ser leídos por quien conoce sólo las frases, estos memes cumplen cierta función pedagógica, pues amplía el conocimiento al relacionar las citas con sus autores (aunque de Pascal sólo aparece su nombre de pila), en un ejercicio paródico de traducción al lenguaje vulgar, con predominancia en español latinoamericano.

Figura 7. Wittgenstein

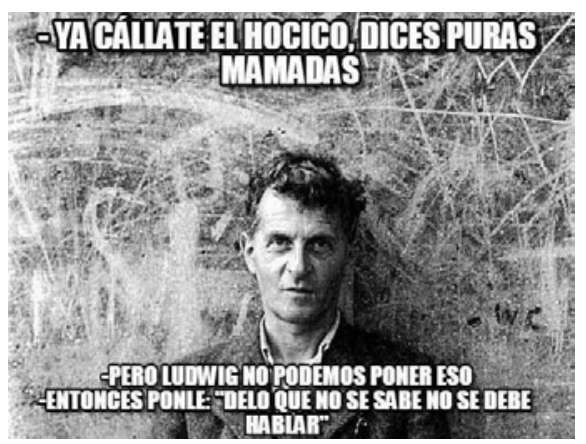

En todo caso se observa en estos memes cierto afán y defensa de un uso del lenguaje sencillo, común y espontáneo.

En los siguientes casos (figuras 7 y 8 ) tenemos una descontextualización y desvirtualización de la cita original, desplazando sensiblemente el sentido original de la frase. Aunque de nuevo se exige en la figura 7 el reconocimiento del rostro del filósofo Wittgenstein, así como su nombre de pila, y relacionarlo con la frase que escribe en su Tractatus "De lo que no se puede hablar hay que callar." (Tractatus lógico-philosophicus, 1922: 7). El sentido de la cita original es trasladado como el de la figura 6 , pero sin dejar de tener una cierta afinidad con el sentido original. Se emplea como si fuera una situación en la que a Wittgenstein, le molesta lo que dice alguien que de nuevo no vemos, cuando se trata de una sentencia con la que pretendía poner fin a las disertaciones metafísicas sobre el mundo.

Figura 8. Kropotkin

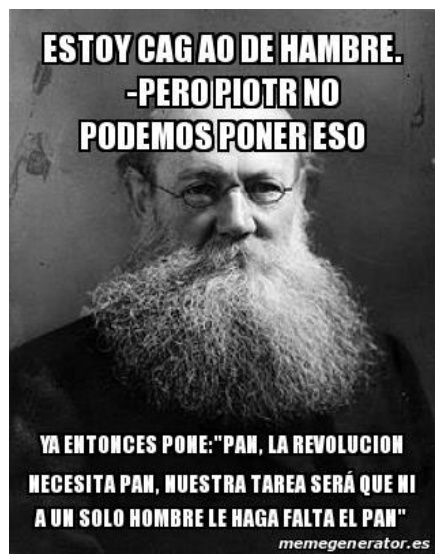


La de Kropotkin (figura 8) sigue el mismo esquema y estructura, juega frivolizando la conocida vindicación de su obra La conquista del pan, donde exigía los derechos de las clases explotadas. Ambos personajes son mucho menos conocidos fuera de sus disciplinas, al igual que sus frases, por lo que exigen del receptor una enciclopedia más amplia y específica, de conocimientos históricos, filosóficos y políticos. No son de uso común ni forman parte del imaginario hegemónico como las anteriores. No obstante operan de igual manera, descontextualizando los enunciados, en el caso de Kropotkin, la frase que se comprende como una exigencia universal se ridiculiza a partir de un hipotético caso en el que la propia hambre le hiciera protestar: pido el pan para el pueblo, porque "yo, Piotr" tengo hambre. Según el nivel de conocimiento del personaje, podría interpretarse como una ironía referida a su condición de hijo de latifundistas. Aunque renunció a gran parte de sus posesiones y vivió en el campo, de forma modesta, cultivando su huerta y fabricando sus propios muebles, gracias a su formación nunca le faltó de nada. Es decir, no se interpreta en ningún momento como una persona que pasase penurias y padeciese graves carestías, a no ser que se aluda al período que permaneció en prisión en muy penosas circunstancias, lo cual supondría la risa propia de la crueldad "satánica" ante la caída ajena que señala Baudelaire (1988). Por tanto el enunciado adquiere muy diversas connotaciones según los datos que ma- neje el receptor sobre el autor y su obra.

Señalemos por último, que a diferencia del primer apartado, aquí sí son relevantes la afectividad y la ironía, y se apunta también en algunos casos, sobre todo en las figuras 7 y 8 , al carácter del humor propio de una comunidad de sentido o gremio dentro de un imaginario y una ideología propios, más o menos restringido. No obstante será en el siguiente apartado donde trataremos los memes de contenido más específico.

\subsection{Crítica, psicoanálisis y humor}

Freud elaboró sus teorías sobre la risa en base a la estructura de los chistes orales tradicionales, lo cual se mantiene en muchos memes. Nos ha parecido apropiado para ilustrar su pensamiento en torno al humor, emplear algunos memes en los que Freud y algunas de sus ideas son tratadas cómicamente. La parodia y la simplificación de sus teorías están muy divulgadas y esta sátira se refleja en una gran multitud de memes semejantes a los que presentamos en las figuras 9 y 10 . Estos textos verbovisuales funcionan como una clásica viñeta donde el reconocimiento del rostro del pensador. En ellas Freud se dirige directamente al receptor del texto, y dice lo que Freud por ser Freud tiene que decir, o sea, lo que se espera de él por parte del imaginario hegemónico. 
Figura 9. Freud

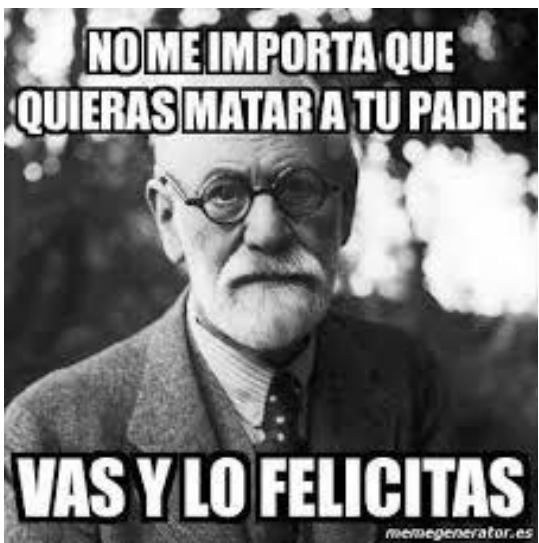

En la figura 9 el humor se obtiene a partir de un mito hegemónico, que es el complejo de Edipo, por lo que el posible destinatario competente para interpretar este meme es menos restrictivo. Jugando con los propios conceptos de Freud, podría decirse que la autoridad que se confiere hegemónicamente a una eminencia del pensamiento como Freud le coloca simbólicamente en el lugar de padre represor: no puedes matar a tu padre, debes fingir que le quieres, honrarle, debes cumplir las convenciones sociales. El meme de Freud aboga aquí por el cumplimiento de la norma social tras reconocer y controlar el deseo inconsciente. La risa a veces emerge como defensa ante afirmaciones que nos delatan y que en cierto modo nos hacen sentir incómodos. En este caso el meme llama la atención a través del complejo edípico que se pretende una acusación universal de deseo incestuoso hacia la población masculina. Su explicitud capta rápidamente la atención, quitando importan-
Figura 10. Freud

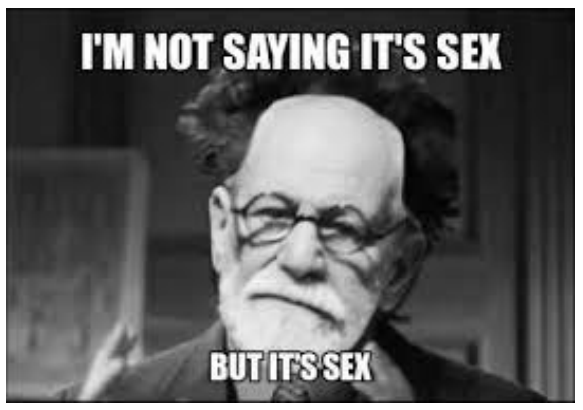

cia a uno de los mayores tabúes sociales, que se debilita en la expectativa de que será lo que suaviza o matiza la conocida teoría. Así, al despertar el interés se produce, según el psicoanálisis, un incremento de libido que inviste el preconsciente, es decir, una preparación para el placer frente a la representación-expectativa de un juego de palabras liberador. Este placer previo predispone para el resultado final: esperamos reírnos, disfrutar, y de esta forma se trata de sobornar al receptor confundiéndole con ingenio para sorprender su alerta crítica y lograr su complicidad, posibilitando que un enunciado desconcertante adquiera de súbito un sentido nuevo que ilumina lo prohibido. La risa estalla cuando un monto de energía psíquica que se utilizaba para provocar la represión, se desinhibe libremente porque esta se volvió innecesaria fugazmente. El meme, como el chiste, consigue mediante el humor que por un momento las pulsiones parciales perversas adquieran un 
estatuto social con sentido (y compartido), y por tanto un placer que surge de una fantasía común, que como tal se tolera, al ir disfrazada de comicidad: no es en serio.

Resulta interesante en estos memes no pasar por alto un breve apunte desde una perspectiva feminista. Si pensamos en una receptora femenina, siendo fieles a la teoría freudiana, deberíamos decir que una mujer no sería un receptor apropiado, que el enunciatario debería ser varón. No obstante, la impuesta mirada masculina hegemónica que ya hace tiempo denunció Mulvey, se constata en este meme que comparten y del que se ríen por las redes tanto hombres como mujeres, acostumbradas a mirar a través del prisma patriarcal las mujeres asumen el hábito de subsumirse a la universalidad objetiva masculina, (heterosexual, blanca y occidental) y les resulta más fácil comprender y reírse de chistes que no la tienen en cuenta, que a un hombre empatizar al leer algo similar pero inverso. Para un varón, una alusión al mito de Edipo invertido, en un supuesto meme en el que Freud dijera: "No me importa que quieras acostarte con tu padre... vas y felicitas a tu madre", sería difícilmente asimilable, incluso poco chistoso para un varón cis heterosexual. Por lo tanto, el imaginario patriarcal está inserto en la enunciación de este texto verbo-visual.

En la figura 10 Freud también mira al frente, de nuevo apelando a un interlocutor que coincide con el receptor, (en este caso el sexo u orientación sexual del receptor no es relevante) y en la primera frase que se atribuye el psicoanalista, se niega aparentemente la extendida caricatura sobre su obsesión por el sexo: Freud dice que no está diciendo que sea sexo. La risa surge de la segunda frase, que al contradecir a la primera refuerza la representación típica del psicoanálisis freudiano: el psicoanalista no dice nada, no es él quien ve "sexo" en todas partes, es que el sexo se encuentra por doquier, y emerge del inconsciente del paciente en múltiples formas, como traducción simbólica de ese impulso omnipresente y censurado. Se mantiene así intacta la visión extendida de la teoría freudiana, reducida al sexo, propiciando una liberación, una compensación a la represión libidinal mediante un subterfugio, el del humor, que canaliza esa necesidad y otorga cierto placer, un placer como una sombra del placer original, pero placer al fin y al cabo.

Observaremos algo similar en las figuras 11 y 12, donde al singular tándem amoroso, amistoso e intelectual, que formaron los filósofos y novelistas Simone de Beauvoir y Jean Paul Sartre. De nuevo aquí lo ideológico y afectivo son fundamentales, de hecho estos memes exigen un conocimiento amplio de ambos filósofos para ser comprendidos, pero además, desde el punto de vista del humor, serán mejor recibidos desde una perspectiva feminista. Es decir, el público al que van destinados resulta ser un grupo más restringido que en todos los anteriores casos. 
Figura 11. Simone de Beauvoir

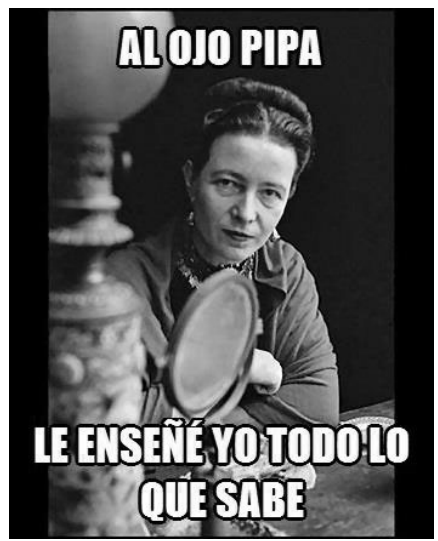

El humor basado en el desprecio del aspecto físico que observamos en ambos memes ejemplifica de nuevo el "satanismo" que Baudelaire atribuye a lo "cómico significativo". No es un humor que apele a la inteligencia ni al ingenio, es una forma de desquite sin gran trascendencia, se basa en la degradación del otro a partir de alguna característica (casi siempre de tipo físico) que se considera un defecto o debilidad. En estos memes la comicidad proviene del defecto visual de Sartre: "ojo pipa" (figura 11) "pinche bizco" (figura 12). Desde la óptica de la moral cristiana, dice Baudelaire, quien ríe lo hace desde una contradicción íntima, desde la consciencia de la propia vulnerabilidad, pero a la vez desde la superioridad que otorga sentirse superior ante la debilidad de otro, ante su deformidad, error, fatalidad o caída:
Figura 12. S. de Beauvoir y Jean Paul Sartre

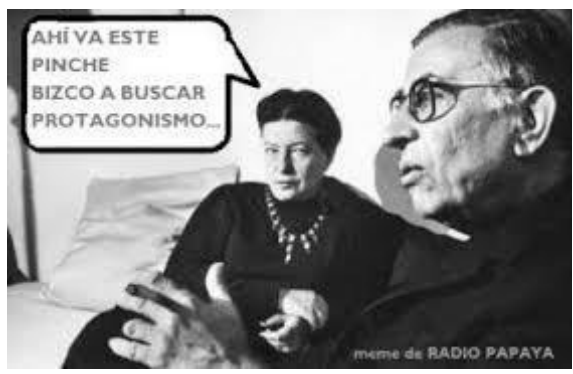

(...) encontraremos en el pensamiento del que ríe cierto orgullo inconsciente. Es el punto de partida: yo no me caigo; yo, camino derecho; yo, mi pie es firme y seguro. No sería yo quien cometería la tontería de no ver una acera cortada o un adoquín que cierra el paso. (...) la escuela satánica, ha comprendido bien esta ley primordial de la risa (Baudelaire, 1988: 24).

Se observa aquí el elemento "satánico" inherente según Baudelaire a la risa, a lo cómico, en el que desde la altura observamos la desgracia ajena, donde la persona que ríe parte de un sentimiento (idea) de superioridad respecto a su objeto de mofa, recurriendo además al elemento igualador del humor. Pero además de recurrir al insulto, se pone en tela de juicio la superioridad intelectual de Sartre sobre Beauvoir atribuyendo 
una mayor valía a Beauvoir, destacando la legendaria melomanía de Sartre, y recordando las facilidades que tuvo como hombre para ser reconocido socialmente. Estos memes funcionan el humor indignado llega a invertir el tópico de la superioridad masculina al afirmarse en la figura 11 que fue Simone quien le enseñó todo a Jean Paul, y así en la fotografía su mirada es leída como enojo. En la figura 12 se aplica también el efecto Kulechov, pero aquí para mostrar a Simone molesta por estar en segundo plano, lo cual irónicamente podríamos conectar con su fundamental aportación al feminismo El segundo sexo. El humorismo puede definirse en estos memes conforme al sentimiento de lo contrario:

Cada vez que me encuentro ante una representación verdaderamente humorística, mi estado de ánimo es de perplejidad, me encuentro entre dos aguas. Me quiero reír, me río, pero la risa se me turba y se me obstaculiza debido a algo que me inspira la misma representación (Pirandello, 2007: 85).

Observamos en este sentimiento a partir de la reflexión que suscita la sorpresa la función del humor como desestabilizador social y político, como forma de denuncia y de desahogo, sirviendo la feminista como símbolo para denunciar de forma universal la situación sufrida por las mujeres en el momento presente de la enunciación.
Para captar correctamente estos memes no basta con conocer el estrabismo de Sartre, o las teorías existencialistas de ambos. La vida sentimental y sexual de estos pensadores se entremezcló siempre con su trabajo filosófico, a lo que se alude en los memes, que demuestran y exigen un conocimiento superficial, pero básico de la pareja, sus vidas y su pensamiento. Pese a la popularidad que disfrutaron ambos tanto por separado como juntos, el tópico "detrás de un gran hombre hay una gran mujer" fue un gran lastre para una feminista como Simone, quien tuvo que acarrear con el ser de las primeras profesoras de filosofía en la universidad, mujer soltera e independiente, y por ello ser censurada y acusada de inmoral por su forma de vida. Mientras tanto, Sartre era admirado y considerado como un conquistador y seductor poco agraciado físicamente pero con un gran encanto que le granjeaba un enorme éxito entre sus estudiantes y en los círculos de artistas e intelectuales. Simone fue amante, mejor amiga, compañera y colega de Sartre durante casi toda su vida, su relación no fue convencional, ya que mantenían otras relaciones paralelas e incluso compartían amantes, lo cual le pasó más factura a ella que a él. Paradójicamente, mientras luchaba por el feminismo, reivindicando toda su vida los derechos de las mujeres tanto en la práctica como en sus escritos, ella misma fue objeto de discriminación y desprecio tanto social como académico, incluso por parte 
de su inseparable compañero Sartre, que no se interesó nunca demasiado por la causa de las mujeres.

En ambos memes se expresa este malestar feminista respecto al protagonismo masculino en la Historia de la Filosofía que simboliza Sartre. El humor aquí funciona como catarsis de una realidad insatisfactoria e injusta, como crítica a través de una mujer en concreto de la situación de las mujeres en general.

Sólo se puede soportar el tinglado de lo social gracias al humor, que desface idealmente lo que es irritante que esté tan hecho, tan uniformado, tan en estrados de entronización. El humorista es el gran químico de disolvencias, y si no acaba de ser querido y a veces se oponen a él duramente los autoritarios, es porque es antisocial, y al decir antisocial, antipolítico (Gómez de la Serna, 1928: 351).

Podríamos aplicar aquí también la función que Freud (2012) otorga a la risa como operación defensiva frente a la realidad. El chiste apela en estos memes a la frustración, a una comunidad femenina que siente, desde la empatía del grupo oprimido, la satisfacción de una fantasía de justicia, a través del reconocimiento. El humor indignado y rencoroso supone la liberación de una especie de impotencia, una risa que descompone y desordena las jerarquías al menos desde el plano simbólico. Como bien observa Abadi (1982) este placer no llega a ser un equivalente, sino un sustituto: "una mera reminiscencia nostálgica del azúcar" (Abadi, 1982: 710), un fruto de la complicidad del deseo de los grupos oprimidos frente a los privilegiados, un desquite contra las contradicciones paradójicas del propio feminismo. Insultar a Sartre es una pequeña licencia para tratar de equilibrar la historia: "El goce del chiste es el goce del contrabando. $\mathrm{O}$ sea el de transgredir, pero de un modo tan hábil que el aduanero no tiene más remedio que reírse también.” (Abadi, 1982: 716).

El sentido latente del chiste no es gracioso, su trasfondo de verdad (en este caso angustia o indignación), expone la vulnerabilidad, la opresión o la injusticia. El humor político o de protesta proporciona un placer siempre ficticio, o compensatorio, supone una defensa que permite renegar ilusoriamente de una situación de opresión a través de provocar la risa, propia y ajena, sobre todo reír en comunidad.

El humor a menudo es reivindicativo, cuestionador y transgresor, se pone del lado de la protesta y de la lucha contra la coerción y el sometimiento. Así, desde una perspectiva social, la risa, el humor, supone desde siempre un vigoroso contrapoder popular, que es capaz de poner en tela de juicio y subvertir el orden social contra los poderosos. Los memes continúan en algunas de sus tipologías este afán político y crítico que ya desarrollaron en otras épocas tiras cómicas, caricaturas, graffitis, etc. 


\subsection{Filosofía y cultura de masas}

Para concluir este breve acercamiento al humor en los memes, vamos a recurrir a los más populares, pero a la vez más restrictivos, pues presuponen pertenecer a una determinada generación,

Figura 13. Hegel

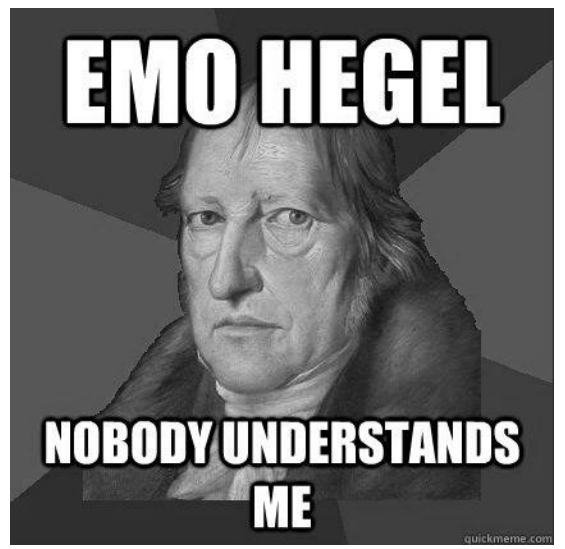

Estos ejemplos (figuras 13 y 14) juegan con el anacronismo, manejando estilos o modas contemporáneas, estéticas muy concretas propias de dos subculturas del siglo XXI, presuponiendo que el receptor las conoce. La figura 13 alude a los "emos", una subcultura adolescente, que se hizo muy popular hace una década. Se caracteriza por una estética post-punk, influenciada por el manga japonés, la literatura gótica y el death metal musical, y caracterizada sobre todo por mantener una actitud nihilista y quejumbrosa, que hace hincapié en el desprecio del mundo y de la vida, debido a sentirse incomprendido y solitario. Se hicieron famosos y fue- cultura y formación. Un humor atravesado por relatos y personajes de la cultura de masas, en cuya intersección se producen collages que mezclan la cultura pop con la filosofía, monstruos grotescos que miran al receptor y le obligan a mirarse a sí mismo.

Figura 14. Nietzsche

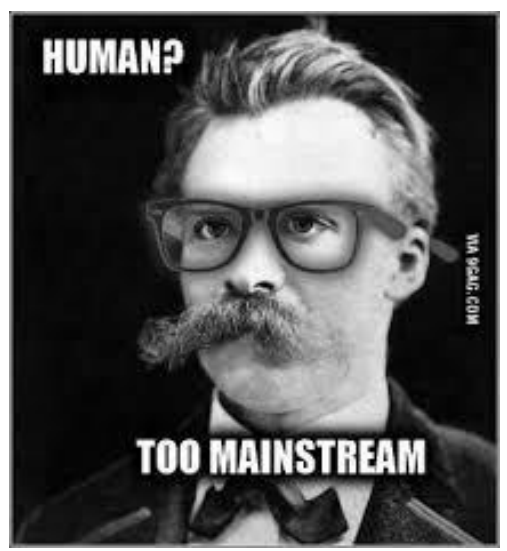

ron motivo de mofa durante mucho tiempo por los selfies que se hacían con un largo flequillo que les ocultaba un ojo (a Hegel a penas le cae un mechón de pelo en medio de la frente) afirmando sentirse desolados y desear la muerte. Al comparar a Hegel con un emo, se hace referencia de nuevo a la dificultad de leer su obra, así como a las diversas y contradictorias lecturas e interpretaciones que se han hecho sobre su filosofía.

El meme de Nietzsche (figura 14) le equipara estéticamente con los hipsters por dos razones: por las gafas que identifican el estereotipo de 
intelectual, y porque además también se presupone que entre los autores predilectos de esta moda urbana se encuentra Nietzsche. La de los hipster es una subcultura muy popular en la actualidad. Se relaciona con el elitismo cultural y bohemio, con una estética vintage, música indie y consumo de alimentos orgánicos y productos de pequeños comercios locales. Se vincula principalmente con los barrios más gentrificados de las grandes urbes occidentales, a lo que alude la frase de la figura 10 , mediante la transformación paródica del título de Nietzsche "Humano, demasiado humano". Lo mainstream (lo hegemónico, lo débil que se impone para someter a los fuertes) evidentemente sería lo contrario que defendería Nietzsche, opositor a la culturas de masas en su sentido homogeneizador, defensor de la voluntad y lo individual. No obstante, irónica y paradójicamente, el filósofo vitalista se identifica de lo intelectual y rebelde, dentro de la lógica del mercado capitalista, la figura de Nietzsche y su retrato supone un símbolo del movimiento gentrificador de la clase media intelectual.

De nuevo, contra la afirmación de Bergson, encontramos dos ejemplos que requieren de cierta afectividad para incitar a la risa. No moverán a la carcajada a quien no conozca y por tanto no tenga una opinión y una emoción hacia los emos y los hipsters, ya sea simpatía o desprecio, al igual que por ambos filósofos. "Lo cómico, la potencia de la risa está en el que ríe y no en el objeto de la risa" (Baudelaire, 1989: 28). El humor depende totalmente del espectador, de su experiencia y de la época y cultura desde las que son recibidas: "Vemos a través de los ojos de nuestra cultura y de nuestra experiencia de lectores de textos visuales"(Abril, 2012:28), sin ciertas experiencias y conocimientos el humor de estos memes no resulta visible. El anacronismo que crean, al situar a los dos filósofos dentro de dos modas más o menos actuales, perderá su "gracia" e incluso su legibilidad cuando el público receptor desaparezca, es un humor extremadamente caduco. Estos chistes caricaturescos pertenecen al "cómico significativo" de Baudelaire al que aludíamos antes, que frente a lo cómico absoluto, tienen solo la vigencia de unos determinados hechos muy concretos que representan, que “imitan” y perderán su potencia cómica cuando a lo que aluden se olvide, pierda actualidad (Baudelaire, 1989).

Los siguientes memes tienen una proyección más universal. Los rostros de los filósofos adquieren cierto dinamismo, pues se aproximan más al formato del "cómic". En la figura 15 Descartes no mantiene un diálogo con otro interlocutor imaginario, ni tampoco se le cita directamente, aunque se alude a su conocida máxima: "Pienso, luego existo", condición imprescindible para comprender el chiste es conocer esta premisa. 
Figura 15. Descartes

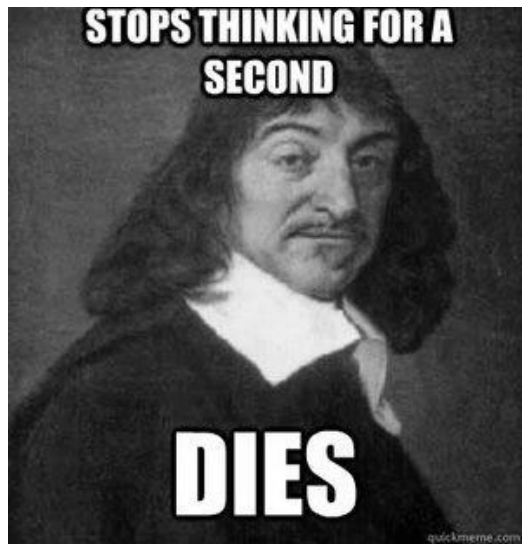

Aquí se emplea la ironía aplicando un esquema lógico básico donde está implícita la famosa frase del racionalista: $\mathrm{a}-\mathrm{b}$ (pensar implica existir), a la que se le añade la negación enunciados lógicos: no a- no b (no pensar implica no existir). De modo que aquí el chiste se basa en exagerar el formalismo lógico y poner en ridículo dicha esquematización. Esta sátira pone en evidencia la afirmación cartesiana, gracias a la porosidad del lenguaje y a la polisemia que potencialmente tiene cualquier enunciado al extraerlo de su contexto. Aquí por tanto se ridiculiza al "racionalista" al aplicar la ley lógica de negación universal a un enunciado particular.

Tanto porque la forma de construir el significado de una situación produce su ritualización, como porque simplemente la deja ver tal cual es, el humor permite también descubrir y
Figura 16. Hume

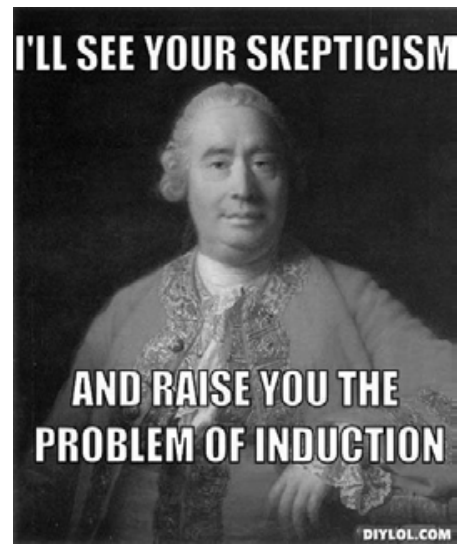

observar con distancia el carácter tópico o convencional de situaciones o temas que normalmente no son puestos en esa tesitura. El humor usa el carácter tópico, formalizado, retórico de las acciones a la prueba de su formalización exagerada y por tanto, convertirlo en cosa de risa (Aladro 2002: 218).

Esta exageración de la rigurosidad lógica racionalista se conjuga con el gesto ausente del filósofo, que mira a un punto indefinido, con las cejas ligeramente arqueadas y un sutil estrabismo, lo que se interpreta, unido con el enunciado, por el efecto Kuleshov, a que se halla con la mente en blanco. Además, al estar muerto, funciona con doble rotundidad el juego, pues se verifica el enunciado con el hecho de que ha muerto realmente (y ha dejado de pensar), lo que evoca el famoso chiste sobre la célebre frase de Nietzsche: 
Figura17. God is dead (Nietzsche)

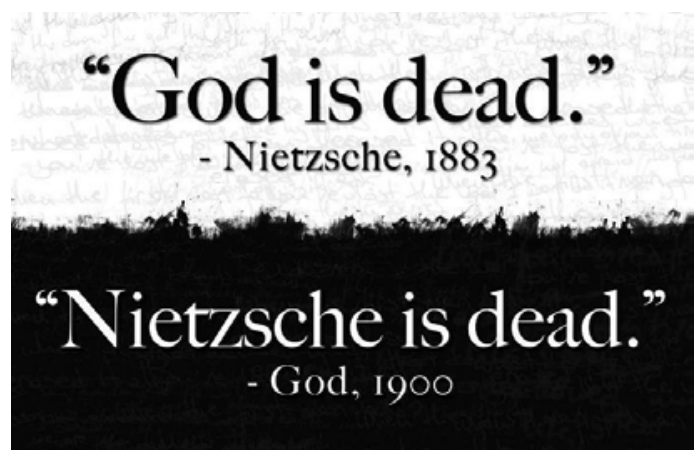

La figura 16 nos muestra a Hume, que nunca trató de disimular su afición al alcohol y al juego. Su pose, por el mismo efecto Kuleshov que en la anterior, se interpreta como retadora y displicente, parece que observa al receptor, interpelándole. La frase, que tampoco es una cita, se interpreta en base a su teoría empirista del conocimiento, y se coloca al enunciatario en el lugar de un virtual oponente en una partida de póker, en la que se juega con los conceptos filosóficos escepticismo y la crítica al principio de causalidad.

Figura 18. Foucault/He Man

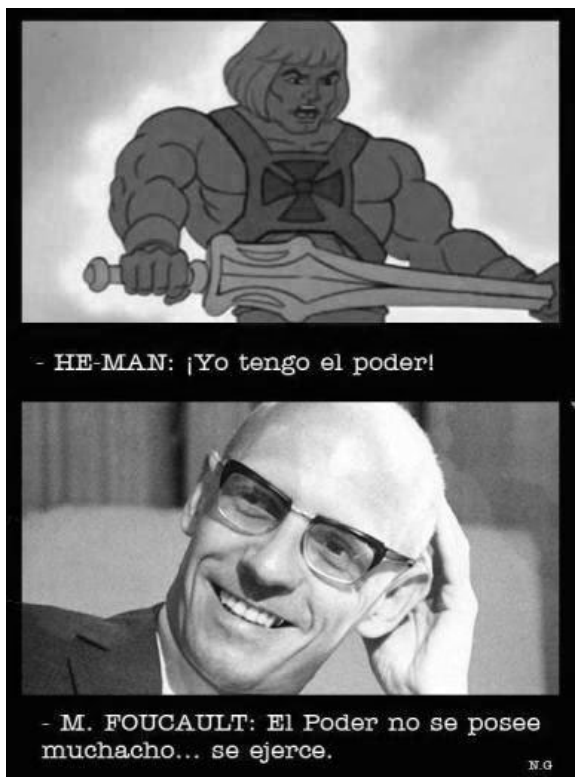


Este meme contrapone el concepto de poder de Foucault a una serie infantil de animación: He Man y los Masters del Universo retransmitida en España y Latinoamérica entre principios de los años 80 y finales de los 90. Es decir, no sólo exige un dominio conceptual de la teoría foucaultiana, sino que además está apelando al reconocimiento de unos grupos de edad concretos que conocen la serie porque la vieron en su infancia o preadolescencia, y reconocen inmediatamente la frase con la que el protagonista invocaba el poder de su espada antes de un enfrentamiento. Para que resulte risible deben unirse las dos experiencias, es necesario que se conozcan los dos marcos que se contraponen: "El acto bisociativo conecta dos matrices de experiencia previamente desconectadas" (Koestler, 2002: 207)". Ambos personajes se contraponen además en el encuadre, empleando el lenguaje verbo-visual del cómic. Foucault, risueño, se burla de un estereotipo hetero-patriarcal cuyo poder procede exclusivamente de su hercúlea musculatura, y de una espada mágica. Aquí la risa no procede de la burla hacia el filósofo, sino de la mofa de un superhéroe que acompañó a varias generaciones de niñas y niños: se parte una vez más de una matriz de sentido atravesada por la emoción y la afectividad. Ver a He Man apela a la infancia, enternece, conmueve, emociona. Foucault apela a nuestro intelecto, indiferentemente de si sus teorías o él mismo, despiertan simpatía o antipatía. Contraponer ambos conceptos de poder, desconcierta al lector competente, y apela a las contradicciones de quien admiraba a He Man y lee a Foucault.

El humorista ha solucionado su problema al unir dos matrices incompatibles en una síntesis paradójica. Su público, por otro lado, ve sus expectativas truncadas y su razón convulsa por el impacto de una segunda matriz tras la primera; en lugar de fusión hay colisión; y el caos mental que sigue favorece que la emoción, desertada por la razón, explote en risas (Koestler, 2002: 219).

La risa explota, efectivamente, por el choque cognitivo, en el que se genera una expectativa emocional, y se resuelve con un jarro de agua fría teórico, intelectual. Desde la perspectiva aparentemente simplista del dibujo animado, se enaltece una visión normativa de la masculinidad, y Foucault, que denuncia los mecanismos y dispositivos que se ejercen sobre los cuerpos en las relaciones de poder, nos lo hace evidente, en su "Historia de la sexualidad" ridiculizando y apelando directamente al héroe o en este caso, que queda así desmitificado. La degradación provoca la risa, la caída de los héroes nos aproxima a lo grotesco. Aunque también la imagen corre el riesgo de perder vigencia, es cierto que un hombre musculoso enarbolando una espada, es un símbolo universal, es decir, evoca en el imaginario occidental (y no sólo) las gestas, los relatos de caballerías y los mitos de héroes y guerreros desde la Antigüedad. 
Como ya vimos la "caída" o la "degradación" provocan la risa, como algo "satánico", afirma Baudelaire que ante la caída o la desgracia ajena sentimos una doble contradicción, de superioridad y a la vez de vértigo porque percibimos nuestra propia inferioridad ante la naturaleza. Nos proyectamos en la caída de nuestros ídolos, que se esperpentizan, causando una sensación de desasosiego, al invertir la admiración por desprecio, si nuestros ideales caen, nosotros nos hundimos. A esto es a lo que Baudelaire denomina como "cómico absoluto", (Baudelaire 1989) y es lo que nos provoca la risa sin freno, la sensación de lo grotesco, que nos hace reír no de lo contingente o cotidiano, de un sujeto o suceso concreto, sino de nuestra propia naturaleza, nos señala a nosotros mismos, como objeto de risa absoluto. Nos reímos al vernos reflejados en nuestras quimeras. $\mathrm{Al}$ desnudar los sueños de infancia y contemplarlos consumidos, al observar estos sueños reducidos a tristes caricaturas deformes que señalan al receptor, éste quiere huir. Pero no es posible huir de nuestra imagen, así que solo queda dejarse vencer por el estrépito de las propias carcajadas de impotencia que fluyen ante ella.

\section{Conclusiones}

Los memes como elemento de análisis dentro del campo de la Semiótica nos ayudan a interpretar cómo funciona la comunicación a través de las redes, y cómo se mantienen, consoli- dan y expanden culturas y comunidades físicas en lo virtual mediante el humorismo. En el caso de los memes sobre pensadores y filósofos, se observa claramente la función que cumple el humor como vínculo social. De hecho a través de esta temática observamos que los memes no inventan nada, sus estructuras repiten fórmulas tradicionales: el collage, la sátira, el chiste, la parodia, la caricatura, la viñeta, el juego de palabras, el absurdo, etc. Como fenómeno de la cultura de masas y como creación popular, reúne elementos tradicionales de la comicidad, a través de las nuevas herramientas digitales que permiten que cualquier creación pueda ser compartida a nivel masivo y reforzando lazos más allá de las fronteras geográficas. Gracias a su rápida transmisión y asimilación, los memes crean y refuerzan comunidades de sentido, gremios o grupos sociales, dando testimonio de las emociones, conocimientos e ideología de determinados grupos, así como reflejando el imaginario común de la época en la que se realizan. En casos como los analizados, se trata de memes que en su inmensa mayoría no se circunscriben a una época concreta, que replican otros formatos previos a Internet, y que son más bien conservadores, manteniendo su temática dentro del canon de la tradición blanca masculina filosófica. No innovan a penas ni en su forma ni en su contenido, por ello su difusión está restringida, sin la repercusión de otros memes masivos o virales como los basados en 
acontecimientos o personajes muy concretos pertenecientes a la televisión, los deportes o a la política (elecciones, escándalos, etc.) y por ello también duran más que otros memes cuya interpretación depende de contextos fluctuantes y anecdóticos con una vigencia breve.

Reírse de un chiste supone participar de la cultura en la que éste se inscribe, pero esto no supone la ausencia de crítica. El humor puede tanto hacer caer estructuras culturales, como reforzar los clichés que la sociedad red hace incluso más globales. La ambivalencia de la risa supone unir a una comunidad en torno a la desacralización de los símbolos, descabezando a través de fórmulas simples, como los memes, los esquemas rígidos y jerárquicos de la sociedad.

\section{Referencias Bibliográficas}

Abadi, M. (1982). Teoría del chiste. Algunas precisiones. Revista de Psicoanálisis № 5. Tomo XXXIX, Buenos Aires.

Abril, G. (2012). Tres dimensiones del texto y de la cultura visual. IC - Revista Científica de Información y Comunicación. Madrid: UCM, pp. 15 - 35.

Aladro, E. (2002). El humor como medio cognitivo. CIC Cuadernos de Información y Comunicación 7, pp. 317-327.

Bajtin, M. (1989). Teoría y estética de la novela. Madrid: Taurus.

Baudelaire, Ch. (1988). Lo cómico y la caricatura. Madrid: Visor.

Bergson, H. (1973). La risa. Ensayo sobre la significación de lo cómico. Madrid: Espasa Calpe.

Castells, M. (2001). La era de la información: economía, sociedad y cultura. Vol I. La sociedad red. Madrid: Alianza.

Deacon, T. W. (2004). Memes as Signs in the Dynamic Logic of Semiosis: Beyond Molecular Science and Computation Theory. Conceptual Structures at Work., Vol. 3127 of the series Lecture Notes in Computer Science, pp 17-31.

Freud, S. (2012). El chiste y su relación con lo Inconsciente. Madrid: Alianza.

Gómez de la Serna, R. (1928). Gravedad e importancia del humorismo. Revista de Occidente, 28 de febrero, pp. 348-360.

Hall, S. (1997). The Work of Representation In Representation: Cultural Representations and Signifying Practises. Stuart Hall ed. London: Sage Cap. 1, pp. 13-74. 
Kilpinen, E. (2008). Memes versus signs: On the use of meaning concepts about nature and culture. Journal of the International Association for Semiotic Studies, vol. 2008, pp 171, 196.

Knobel, M. y Lankshear, C. (2005). Memes and affinities: Cultural replication and literacy education. $N R C$, Miami, November.

Koestler, A. (2002). El humor como acto cognitivo (El acto de creación: Libro I: El bufón). CIC Cuadernos de Información y Comunicación 7, pp. 317-327.

Pirandello, L. (2007). El humorismo. Madrid: Langre.

Sontag, S. (1995). El amante del volcán. Madrid: ALFAGUARA. 